\title{
EFEK MODERASI SKEPTISISME PROFESIONAL PADA PENGARUH KOMPETENSI DAN KOMPENSASI TERHADAP KINERJA AUDITOR KANTOR AKUNTAN PUBLIK DI PROVINSI BALI
}

\author{
I Dewa Made Arik Permana Putra ${ }^{1}$ \\ Desak Ketut Sintaasih ${ }^{2}$ \\ ${ }^{1}$ Fakultas Ekonomi dan Bisnis, Universitas Udayana, Bali, Indonesia \\ 1email: arikpermanaputra@yahoo.com \\ ${ }^{2}$ Fakultas Ekonomi dan Bisnis, Universitas Udayana, Bali, Indonesia
}

\begin{abstract}
ABSTRAK
Penelitian ini bertujuan untuk menganalisis pengaruh kompetensi terhadap kinerja auditor, menganalisis pengaruh kompensasi pada kinerja auditor terhadap kinerja auditor, untuk menganalisis efek moderasi pada pengaruh kompetensi pada kinerja auditor dan menganalisis efek moderasi pada pengaruh kompensasi terhadap kinerja auditor. Penelitian ini dilakukan pada auditor kantor akuntan publik di Provinsi Bali dengan jumlah responden 67 auditor. Metodepengumpulan data menggunakan metode survei dengan teknik kuesioner. Teknik analisis data menggunakan teknik analisis regresi moderasi.Hasil penelitian menunjukkan bahwa kompetensi berpengaruh positif dan signifikan pada kinerja auditor, kompensasi berpengaruh positif dan signifikan pada kinerja auditor.Sedangkan efek moderasi skeptisisme professionalmemperkuat pengaruh kompetensi terhadap kinerja auditor, demikian juga efek moderasi skeptisisme professional memperkuat pengaruh kompensasi terdap kinerja auditor.
\end{abstract}

Keyword: kinerja auditor, kompetensi, kompensasi, skeptisisme profesional

\begin{abstract}
ABSTRACK
This study aims to analyze the effect of competence on auditor performance, to analyze the effect of compensation on auditor performance on auditor performance, to analyze the effect of moderation on the influence of competence on auditor performance and to analyze the effect of moderation on the influence of compensation on auditor performance. This research was conducted at auditor of public accountant office in Bali Province with respondent amount 67 auditor. Methods of data collection using survey method with questionnaire technique.Data analysis technique used moderation regression analysis technique. The results showed that competence has a positive and significant effect on auditor performance, compensation has positive and significant influence on auditor performance. While the effect of moderation on professional skepticism reinforces the influence of competence on the performance of auditors, as well as the moderate effects of professional skepticism reinforces the compensatory effect of auditor performance.

Keyword: auditor performance, competence, compensation, professional skepticism
\end{abstract}


I Dewa Md. Arik Permana Putra, dan Desak Kt. Sintaasih. Efek Moderasi Skeptisisme.....

\section{PENDAHULUAN}

Sumber daya manusia (SDM) memegang peranan penting dalam pencapaian kinerja organisasi.Kinerja merupakan hasil yang dicapai organisasi, baik organisasi pemerintah maupun swasta.Untuk mencapai kinerja yang tinggi, diperlukan SDM yang memiliki daya kerja yang tinggi, dalam mengantisipasi peluang dan tantangan lingkungan bisnis yang semakin kompetitif.

Dalam organisasi kantorakuntan, SDM-nya adalah seorang auditor yang mengerjakan tugas-tugasnya harus profesional agar dapat memberikan kepuasan kepada klien (audity). Auditor independen adalah auditor yang bertanggung jawab untuk memenuhi standar auditing yang ditetapkan Institut Akuntan Publik Indonesia (Agoes, 2012:31). Auditor ditugaskan untuk mengumpulkan dan memeriksa bukti audit untuk memastikan kesesuaian antara informasi dengan kriteria yang ditetapkan dan kemudian mengkomunikasikan terhadap user. Umam (2010:189) menegaskan kinerja adalah hasil kerja yang dicapai oleh individu sesuai dengan peran atau tugasnya dalam periode tertentu, yang dihubungkan dengan ukuran nilai atau standar tertentu dari organisasi tempat individu tersebut bekerja. Kinerjaauditor seperti dikemukakan oleh Kalbert dan Forgarty (1995) dalam Trisnaningsih (2007) adalah sebagai evaluasi terhadap pekerjaan yang dilakukan oleh atasan, rekan kerja, diri sendiri dan bawahan langsung.

Ayudiati (2010) menyebutkan bahwa peningkatan kinerja dalam pekerjaannya dipengaruhi oleh kondisi-kondisi tertentu, yaitu kondisi yang berasal dari dalam individu yang disebut disebut faktor individual dan kondisi yang berasal dari luar individu yang disebut faktor situasional. 
Pengaruh kompetensi dan kompensasi terhadap kinerja merupakan fenomena menarik dan penting untuk diteliti. Fenomena pertama mengenai temuan empiris hasil penelitian, kompetensi terhadap kinerja temuan penelitiannya menunjukkan hasil yang tidak konsisten. Hasil penelitian pertama menemukan bahwa kompetensi berpengaruh pada kinerja (Emmyah. 2009), (Dhermawan dkk.,2012), (Safwan dkk., 2014). Sedangkan hasil penelitian kedua menemukan bahwa kompetensi tidak bepengaruh pada kinerja (Ghani, 2016),(Supiyanto, 2015), dan (Wardhana dkk., 2015). Hal ini juga didukung oleh survei awal pendahuluan peneliti, yang dilakukan pada Kantor Akuntan Publik I Wayan Ramantha khususnya di Koperasi Jasa Audit Kertha Yasa Provinsi Bali sebagai kantor unitnya ditemukan bahwa terdapat kontrak kerja audit dan penyelesaian laporan auditor independen yang tidak lewat waktu. Tabel 1.1 menunjukkan data kontrak kerja audit dengan penyelesaian laporan auditor independen tahun buku 2016.

Tabel 1.1 menunjukkan bahwa dua klien (audity) penyelesaian laporan audit tepat waktu (bahkan kurang dari kontrak kerja penyelesaian laporan audit), sedangkan delapan klien penyelesaian laporan audit melewati batas waktu penyelesaian audit. Hal ini menunjukkan bahwa kinerja auditor masih kurang atau auditor tidak dapat menyelesaikan laporan auditnya dengan tepat waktu.

Hasil penelitian sebelumnya mengenai pengaruh kompensasi terhadap kinerja, menunjukkan hasil yang tidak konsisten, artinya kompensasi berpengaruh positif dan signifikan pada kinerja (Supatmi dkk., 2010), (Dito, 2010), dan (Mahmun dkk., 2010). Sedangkan kompensasi tidak berpengaruh pada kinerja 
I Dewa Md. Arik Permana Putra, dan Desak Kt. Sintaasih. Efek Moderasi Skeptisisme.....

karyawan (Riyadi 2011, Listianingsih, 2010, Rahmawati, 2009, Kristina, 2012, Widyarto, 2012, Afnita, Mahlia, Umar, 2014)

Tabel 1.1

Daftar Penyelesaian Laporan Auditor Independen Pada Klien (Audity) Tahun buku 2016

\begin{tabular}{clcccl}
\hline No & \multicolumn{1}{c}{ Klien } & $\begin{array}{c}\text { Mulai } \\
\text { Kontrak } \\
\text { Kerja Audit }\end{array}$ & $\begin{array}{c}\text { Penyelesaian } \\
\text { Kontrak } \\
\text { Audit }\end{array}$ & $\begin{array}{c}\text { Penyelesaian } \\
\text { Laporan Audit }\end{array}$ & Keterangan \\
\hline 1 & KUD Penebel & $13-09-2016$ & $13-03-2017$ & $15-04-2017$ & Lewat 15 hari \\
2 & Puskud Bali Dwipa & $27-11-2016$ & $27-03-2017$ & $20-04-2017$ & Lewat 24 hari \\
3 & KSU Pemogan & $29-08-2016$ & $01-03-2017$ & $05-03-2017$ & Lewat 4 hari \\
4 & KSU Kuta Mimba & $23-07-2016$ & $28-02-2017$ & $01-03-2017$ & Lewat 1 hari \\
5 & Koperasi Laksmi & $23-08-2016$ & $20-02-2017$ & $25-02-2017$ & Lewat 5 hari \\
6 & KSP Payangan & $17-07-2016$ & $25-01-2017$ & $15-01-2017$ & Tepat waktu \\
7 & KUD Dapdapputih & $20-06-2016$ & $20-01-2017$ & $15-02-2017$ & Lewat 25 hari \\
8 & Koppas Sri Nadi & $30-06-2016$ & $31-01-2017$ & $02-02-2017$ & Lewat 2 hari \\
9 & KPN BinaSejahtera & $30-09-2016$ & $29-01-2017$ & $05-02-2017$ & Lewat 7 hari \\
10 & KUD Payangan & $17-07-2016$ & $25-01-2017$ & $15-01-2017$ & Tepat waktu \\
\hline
\end{tabular}

Sumber: Buku Register Audit Koperasi Jasa Audit Kertha Yasa Provinsi Bali (2017)

Hasil dari wawancara peneliti dengan auditor (I Putu Artana) di KAP I Wayan Ramantha menunjukkan bahwa kompensasi yang diberikan kepada auditor berkisar antara 5-10 persen dari kontrak kerja audit.Dengan kompensasi yang memadai dan kompetensi yang dimiliki oleh auditor, secara teori semestinya ke dua variabel ini berpengaruh pada kinerja.Maka menurut Hartono (2004) mengemukakan bahwa apabila penelitian-penelitian sebelumnya yang menemukan hubungan kausal yang saling bertentangan, baik signifikansinya ataupun arahnya, kemungkinan disebabkan oleh variabel lain yang memoderasi hubungan kausal tersebut.

Arfah dan Anshori, (2005: 372) mengemukakan bahwa betapapun sempurnanya rencana organisasi dan pengawasan. Di mana saat ini dihadapkan masalah menurunnya jumlah klien, dan meningkatnya jumlah absensi auditor 
dapat dilihat pada data absensi auditor dan data klien jasa pengauditan tahun 2012 - 2016. Data absensi auditorditunjukkan pada Tabel 1.2 dan data daftar klien disajikan pada Tabel 1.3

Tabel 1.2

Data Absensi Auditor Koperasi Jasa Audit Kertha Yasa Provinsi Bali Tahun 2012- 2016

\begin{tabular}{lcccccc}
\hline Tahun & $\begin{array}{c}\text { Jumlah } \\
\text { Auditor }\end{array}$ & Sakit & Ijin & Cuti & $\begin{array}{c}\text { Mangkir/ } \\
\text { Bolos }\end{array}$ & $\begin{array}{c}\text { Jumlah } \\
\text { Absen }\end{array}$ \\
\hline 2012 & 15 & 1 & 2 & - & 1 & 4 \\
2013 & 17 & 2 & 1 & 1 & 2 & 6 \\
2014 & 17 & 3 & 2 & 2 & 3 & 10 \\
2015 & 18 & 2 & 2 & 5 & 2 & 12 \\
2016 & 17 & 2 & 5 & 3 & 13 \\
\hline Sumber: Koperasi Jasa Audit Kertha Yasa Provinsi Bali (2017)
\end{tabular}

Data daftar klien ditunjukkan pada Tabel 1.3, secara keseluruhan mekanisme termasuk prosedur pengauditan auditor ke klien hampir merata. Berikut daftar klien yang ditunjukkan Koperasi Jasa Audit Provinsi Bali tahun 2012-2016.Berdasarkan Tabel 1.2 dan 1.3 dapat dilihat bahwa Koperasi Jasa Audit Kertha Yasa Provinsi Bali mengalami penurunan jumlah klien dari tahun 2012-2016 dan peningkatan jumlah absensi auditor pada tahun 2012-2016.

Tabel 1.3

Daftar Klien Jasa Koperasi Jasa Audit Kertha Yasa Provinsi Bali Tahun 2012-2016

\begin{tabular}{cccccc}
\hline Jenis Jasa & $\mathbf{2 0 1 2}$ & $\mathbf{2 0 1 3}$ & $\mathbf{2 0 1 4}$ & $\mathbf{2 0 1 5}$ & $\mathbf{2 0 1 6}$ \\
\hline Audit general & 120 & 115 & 112 & 111 & 110 \\
Audit special & 17 & 20 & 23 & 20 & 15 \\
Jumlah & 137 & 136 & 135 & 131 & 125 \\
\hline
\end{tabular}

Sumber: Koperasi Jasa Audit Kertha Yasa Provinsi Bali (2017)

Jumlah klien tahun 2012-2016 dan peningkatan jumlah absensi auditor pada tahun 2006-2016.Diindikasikan kondisi kerja para karyawan yang kurang baik karena rendahnya tingkat kompensasi terhadap karyawan.Dapat dilihat dari jumlah ketidakhadiran karyawan yang semakin meningkat hal ini 
I Dewa Md. Arik Permana Putra, dan Desak Kt. Sintaasih. Efek Moderasi Skeptisisme.....

disebabkan karena tidak terpenuhinya jumlah kompensasi yang diharapkan oleh para karyawan.

Badera (2004) menyatakan adanya kesatuan hasil penelitian pengaruh satu varibel terhadap variabel lain kemungkinan tergantung pada faktor-faktor situasional (kontekstual). Penelitian berkaitan dengan pengaruh kompetensi dan kompensasi terhadap kinerja karyawan dengan menghadopsi pendekatan kontijensi, dilakukan oleh Brownell (1982), Sutrisno (2010), Jalaludin (2010). Selaras dengan Badera (2004), adalah penjelasan yang dinyatakan oleh Hartono (2004) yang mengemukakan bahwa apabila penelitian-penelitian sebelumnya yang menemukan hubungan kausal yang saling bertentangan, baik signifikansinya ataupun arahnya, kemungkinan disebabkan oleh variabel lain yang memoderasi hubungan kausal tersebut.

Azad (1994) menemukan bahwakaryawan yang bekerja dengan tekanan kompetetifwaktucenderung disfungsionalis, terlalu percaya pada penjelasan kolega, serta gagal dalam menginvestigasi isu-isu relevan dalam mendeteksi kecurangan.Faktor-faktor yang menyebabkan auditor gagal mendeteksi kecurangan, menurut hasil penelitian Sugianto (2009) adalah kurangnya kompetensi, kurangnya kecermatan dan kehati-hatian profesional termasuk skeptisisme profesional.Oleh karenaitu untuk dapat membuktikan hal tersebut, maka diperlukan penelitian yang lebih mendalam tentang: "Efek Moderasi Skeptisisme Profesional pada Pengaruh Kompetensi dan Kompensasi terhadap Kinerja Auditor Kantor Akuntan Publik di Provinsi Bali”. 


\section{Pengaruh Kompetensi terhadap Kinerja Auditor Kantor Akuntan Publik di Provinsi Bali}

Kompetensi merupakan modal dasar dalam setiap pelaksanaan suatu pekerjaan dalam bentukdan lingkup pekerjaannya, karena itu auditor akan lebih kreatif untuk bekerja secara efisien dan efektif dalam mencapai hasil kerja yang optimal yang pada akhirnya dapat mencapai tujuan yang telah ditetapkan organisasi (Nizarul dkk., 2007). Pernyataan ini konsisten dengan pernyataan Lotunani et al., (2014) yakni kompetensi karyawan berpengaruh dan signifikan pada kinerja karyawan tapi tidak signfikan ketika dimediasi oleh kepuasan kerja, hal ini sama pendapatnya dengan Anguo Xu dan Long Ye (2014) yakni kompetensi guru berpengaruh positif pada kinerja tugasnya dan sesuai dengan bidang tugasnya.

Kompentensi selalu mengandung maksud dan tujuan yang merupakan dorongan motif atau tarif yang menyebabkan suatu tindakan untuk memperoleh hasil kinerja yang baik. Hal ini seirama dengan pendapat Rahmah Ismail dan Syahida Zainal Abidin (2010) yakni Semakin meningkat kompetensi satuan pekerja di perusahan sektor publik semakin meningkat pula kinerja pekerjanya, studi ini dilakukan pada sektor jasa swasta di malaysia. Hal ini dipertegas oleh Rantesalu et al., (2016) yang menyatakan Kompetensi berpengaruh postif dan signifikan pada kinerja karyawan, sedangkan Kolibáčová (2014) berargumen semakin meningkat kompetensi karyawan maka kinerja karyawan akan meningkat pula. Bahkan Rahmah and Syahida (2010) menemukan indeks kompetensi akan mengembangkan dan secara substansi akan 
I Dewa Md. Arik Permana Putra, dan Desak Kt. Sintaasih. Efek Moderasi Skeptisisme.....

meningkatkan secara signifikan pada kinerja pekerja. Pendapat yang sama juga disampaikan oleh Halil et al., (2013)semakin meningkat kompetensi individu akan semakin meningkat pula kinerj organisasi.Berdasarkan hasil-hasil penelitian di atas maka hubungan kompetensi dengan kinerja auditor dapat dirumuskan hipotesis sebagai berikut:

Hipotesis $_{1:} \quad$ Kompetensi berpengaruh positif terhadap kinrerja auditor kantor akuntan publik di provinsi Bali

\section{Pengaruh Kompensasi terhadap Kinerja Auditor Kantor Akuntan Publik di Provinsi Bali}

Kompensasi yang diberikan harus menggambarkan nilai dari suatu pekerjaan yang telah dicapai, karena itu merupakan suatu bentuk penghargaan atas hasil kerja mereka dalam organisasi sesuai dengan jenis pekerjaan yang mereka lakukan.Hal ini konsisten dengan pendapatnya Emmanuel (2013) yang menyatakan kompensasi berhubungan positip dan signifikan pada produktivitas karyawan dalam industri perbankan di Ghana.Hal ini konsisten dengan peryataan Ibojo dan Asabi (2014) yakni kompensasi berhubungan positif dan signifikan pada kinerja karyawan food and baeverage pada perusahaaan manufaktur.

Hal ini, atasan harus mempunyai peran yang penting dalam usahanya untuk memotivasi dan mengelola karyawannya, hal ini sesuai dengan pernyataan Abdul Hameed et al., (2014) yaitu kompensasi berpengaruh positif dan signifikan pada kinerja karyawan pada sektor perbankan di Pakistan. Sedangkan Patrick (2014) berpendapat bahwa kompensasi memberikan pengaruh yang meningkat sehingga motivasi pekerja semakin meningkat pula. Hal ini 
konsisten dengan pernyataan Ayesha et al., (2015) yakni kompensasi, isentif dan gaji berpengaruh positif dan signifikan pada kinerja organisasi sektor perbankan di pakistan. Jadi, hubungan antara kompensasi dengan kinerja auditor dirumuskan hipotesis sebagai berikut:

Hipotesis ${ }_{2}$ : Kompensasi berpengaruh positif terhadap kinerja auditor Kantor Akuntan Publik di Provinsi Bali

\section{Efek Moderasi Skeptisisme Profesional pada Pengaruh Kompetensi terhadap Kinerja Auditor kantor Akuntan Publik di Provinsi Bali}

Skeptisisme profesional merupakan sikap karyawan yang mencakup pikiran yang selalu mempertanyakan dan melakukan evaluasi secara kritis terhadap kinerjanya.Sebagaimana telah dipaparkan sebelumnya bahwa skeptisme profesional dengan cermat dan seksama menuntut kinerja untuk melaksanakan skeptisisme profesional menjadi lebih baik (Suzy dan Noviyanti, 2008).Dapat diartikan bahwa skeptisisme profesional menjadi salah satu faktor dalam menentukan kemahiran profesional seorang kinerja auditor (Sutrino dan Fajarwati, 2014). Dengan demikian dapat dikatakan bahwa semakin tinggi tingkat skeptisime seorang auditor dalam melakukan pekerjannya, maka diduga akan berpengaruh pada kinerja auditor tersebut (Gusti dan Ali, 2008). Ketidakmampuan auditor dalam menerapkan skeptisisme professional dalam bekerja akan menggangu hasil pekerjaanya (Kathy Y Hurt (2005). Berdasarkan pemikiran dapat diprediksikan bahwa skeptisisme profesional sebagai moderasi akan mampu memengaruhi kompetensi terhadap kinerja auditor. Sehingga dapat dihipotesiskan sebagai berikut: 
I Dewa Md. Arik Permana Putra, dan Desak Kt. Sintaasih. Efek Moderasi Skeptisisme.....

Hipotesis $_{3}$ : Skeptisisme profesional memoderasi pengaruh kompetensi terhadap kinerja auditor Kantor Akuntan Publik di Provinsi Bali

\section{Efek Moderasi Skeptisisme Profesional sebagai Pemoderasi Pengaruh Kompensasi terhadap Kinerja Auditor Kantor Akuntan Publikdi Provinsi Bali}

Skeptisisme profesional merupakan sikap auditor yang mencakuppikiran yang selalu mempertanyakan dan melakukan evaluasi secara kritis terhadap kinerja auditor.Dapat diartikan bahwa skeptisisme profesional menjadi salah satu faktor dalam menentukan kemahiran auditor (Suzy dan Noviyanti, 2008). Dengan demikian dapat dikatakan bahwa semakin tinggi tingkat skeptisisme seorang auditor dalam bekerja, serta berinteraksi dengan kompensasi maka akan berpengaruh pada kinerja auditor (Gusti dan Ali, 2009). Ketidakmampuan auditor dalam menerapkan skeptisisme professional akan mengganggu kinerja auditor (Patrik, 2014). Berdasarkan hasil-hasil penelitian di atas dapat diprediksikan bahwa skeptisisme profesional akan berinteraksi dengan kompensasi yang akan memengaruhi kinerja auditor, dengan rumusan hipotesis sebagai berikut:

Hipotesis 4: Skeptisisme profesional memoderasi pengaruh kompensasi terhadap kinerja auditor Kantor Akuntan Publik di Provinsi Bali

\section{METODE PENELITIAN}

Metode pengumpukan data yang digunakan dalam penelitian ini adalah menggunakan metode survei dengan teknik kuisiner.Sedangkan 
metode sampling menggunakan metode nonpobabilitas dengan tenik sampling jenuh.Uji instrument yang digunakan uji viliditas dan uji relibilitas.Metode analisis data yang digunakan adalah Metode Analisis regresi Moderasian.

\section{Variabel Penelitian dan Definisi Operasional Variabel}

1) Kompetensi $\left(\mathrm{X}_{1}\right)$ adalah suatu karekteristik dasar seorang auditor yang memengaruhi cara berpikir, cara bertindak dilandasi oleh pengetahuan, keterampilan, dan sikap yang menghasilkan kemampuan untuk melaksanakan suatu pekerjaan yang dapat menghasilkan kinerja tinggi. Indikator dari kompetensi (Kolibacova dan Gabriela 2014, Arumega et al., 2015 dan Rantesalu etal., 2016)sebagai berikut: (1) Konsisten yaitu mengelola dan mengatur pekerjaan audit dapat diselesaikan dengan tepat waktu. (2) Sikap yaitu menyelesaikan tugas audit tanpa terjadi kesalahan. (3) Sistem nilai yaitu tugas yang dikerjakan oleh auditor dengan baik, dan efeknya juga berdampak pada kantornya. (4) Informasi yaitu informasi yang diberikan oleh auditor bahwa auditor yang melaksanakan tugasnya merupakan bagian dari sistem kerja yang ada. (5) Lingkup pekerjaan adalah mendaftarkan informasi dengan pekerjaannya, hingga memahami pekerjaan dengan baik. (6)Kemampuan menyelesaikan tugas teknis adalah kemampuan auditor menyelesaikan kegiatan audit terkait dengan lingkup pekerjaannya.

2) Kompensasi $\left(\mathrm{X}_{2}\right)$ adalah penghargaan yang diterima seorang auditor sebagai imbalan atas jerih payahnya baik berupa uang maupun berupa penghargaan lainnya yang membuat orang tersebut merasa puas atas hasil 
I Dewa Md. Arik Permana Putra, dan Desak Kt. Sintaasih. Efek Moderasi Skeptisisme.....

kerja yang sudah dicapainya. Indikator kompensasi (Bojo dan Asabi, 2014, Hamed et al., 2014, Aslam et al.,2015, dan Patrick, 2014): (1) Gaji adalah gaji yang diterima oleh auditor sesuai dengan pekerjaan auditnya. (2) Upah adalah honor yang diterima oleh auditor yang selalu diberikan tepat waktu oleh KAP. (3) Insentif adalah bonus yang diterima oleh auditor atas pekerjaan yang diselesasikan. (4) Asuransi adalah asuransi yang diterima oleh auditor atas pekerjaan yang diselesasikan. (5) Tunjangan adalah tunjangan yang diterima oleh auditor atas pekerjaan yang diselesasikan. (6) Pensiun adalah dana pensiun yang diterima oleh auditor atas pekerjaan auditnya ketika selesai menjadi auditor.

3) Skeptisisme Profesional $\left(X_{3}\right)$

Skeptisisme profesional karyawan didefinisikan sebagai suatu sikap yang mencakup pikiran yang selalu mempertanyakan dan melakukan evaluasi secara kritis terhadap kinerjanya (IAI, 2011:230.2) dan Noviyanti (2008). Indikator Skeptisisme profesional menurut Qudackers (2009), Hurt (2010), Taylor Hotdtrom (2015), ditunjukkan sebagai berikut:(1) Sikap tekun dan hati-hati adalah sikap yang selalu fokus terhadap pekerjaan dan hati-hati dalam mengumpulkan bukti untuk memberikan keyakinan yang memadai pada apa yang diperiksa. (2) Tidak percaya adalah suatu sikap yang dimiliki oleh auditor yang selalu tidak mudah percaya dengan kinerja yang telah disediakan. (3) Kesalahan pekerjaan adalah sikap kritis yang dimiliki oleh seorang auditor dana selalu bertanya dan evaluasi terhadap pekerjannya. (4)Evaluasi pekerjaan adalah sikap yang dimiki oleh seorang auditor yang 
selalu melakkan evaluasi terhadap pekerjannya. (5) Detail pekerjaan adalahsuatu sikap yang dimiliki olehseorangauditor yang dalam menyelesaikan pekerjaan harus mengumpulkan dengan dukungan yang meyakinkan dengan rinci dan detail.

4) Kinerja Auditor (Y)

Kinerja Auditor adalah hasil kerja yang mampu diperoleh auditor dalam suatu klien yang dinilai baik dari segi kualitas maupun kuantitas dalam melaksanakan tugas-tugas yang dibebankan klien.Indikator yang digunakan untuk mengukur tinggi rendahnya kinerja auditor diadopsi dari Rahmah dan Abidin (2010), yaitu:(1) Prestasi kerja yaitu keterampilan yang dimiliki auditor untuk memecahkan masalahnya sendiri dalam penyelesaian tugas. (2) Tanggung jawab yaitu auditor memiliki rasa tanggung jawab untuk menyelesaikan tugasnya dengan baik. (3) Kejujuran yaitu penyampaian sesuatu yang sesuai dengan keadaan yang sebenarnya. (4) Kerjasama yaitu kemampuan auditor dalam bekerjasama dengan rekan sekerjanya. (5) Inisiatif yaitu kemampuan auditor dalam menyelesaikan tugas dan pekerjaan serta mampu mengambil keputusan dalam keadaan mendesak. (6) Ketepatan waktu yaitu sesuai tidaknya waktu penyelesaian pekerjaan dengan waktu yang ditetapkan sebelumnya. (7) Tingkat kesalahan kerja yaitu kemampuan auditor dalam menyelesaikan pekerjaan dengan baik tanpa adanya kesalahan. (8)Kecepatan kerja yaitu seberapa cepat karyawan mampu menyelesaikan pekerjaan rutin tanpa mengurangi kualitas kerja. 
I Dewa Md. Arik Permana Putra, dan Desak Kt. Sintaasih. Efek Moderasi Skeptisisme.....

\section{Metode Analisis Data}

Teknik analisis data yang digunakan dalam penelitian ini adalah teknik analisis kuantitatif yakni analisis regresi moderasian (Moderated regression analysis).. Teknik analisis yang digunakan sebagai berikut:

$\mathbf{Y}=\alpha+\beta_{1} X_{1}+\beta_{2} X_{2}+\beta_{3} X_{3}+\beta_{4} X_{1} \cdot X_{3}+B_{5} \cdot X_{2} \cdot X_{3}+\varepsilon$

Keterangan:

Y: Kinerja Auditor $\quad \mathrm{X}_{2}$ : Kompensasi

$\alpha: \quad$ Konstanta $\quad \mathrm{X}_{3}$ : Skeptisisme Profesional

$\beta_{1}-\beta_{5}$ : Koefisien Regresic:Error term

$\mathrm{X}_{1}$ : Kompetensi

Secara statistik rumus regresi di atas dapat diamati dari goodness of fit yakni: uji Koefisien determinasi $\left(\mathbf{R}^{\mathbf{2}}\right)$ yakni analisis ini digunakan untuk mengetahui seberapa besar kemampuan model dalam menerangkan variasi variabel terikat (Ghozali, 2002:45). Hasil pengukuran koefisien diterminasi dapat dilihat pada besarnya adjusted $R$ Square.,Uji kelayakan model (F) yaitu apabila hasil uji $\mathrm{F}$ adalah signifikan $\alpha<0,05$ maka variabel bebas dapat memprediksi kinerja auditor.Uji Statistik t yaitu hipotesis akan diterima apabila taraf signifikansinya lebih kecil dari 0,05. Artinya variabel kompetensi $\left(\mathrm{H}_{1}\right)$ dan kompensasi $\left(\mathrm{H}_{2}\right)$ berpengaruh pada kinerja auditor, apabila signifikansi koefisien variabel interaksi Skeptisisme professionnal dibawah 0,05 (5 persen) maka hipotesis moderasi $\left(\mathrm{H}_{3}\right.$ dan $\left.\mathrm{H}_{4}\right)$ diterima.Apabila taraf signifikansinya lebih besar atau sama dengan 0,05 maka hipotesisnya ditolak (Ghozali: 2002: 44). 


\section{HASIL DAN PEMBAHASAN}

Di Bali, kantor akuntan publik yang telah beroperasi adalah yang telah mendapatkan izin dari Menteri untuk memberikan jasa sebagaimana diatur dalam $\quad$ PeraturanMenteri Keuangan Nomor: 17/PMK.01/2008.Pengumpulan data dilakukan melalui penyebaran kuesioner kepada auditordi sembilan Kantor Akuntan Publik di Provinsi Bali yang merupakan anggota Institut Akuntan Publik Indonesia (IAPI). Waktu yang dihabiskan untuk mengumpulkan kuisioner adalah 45 hari yaitu mulai bulan Nopember 2017 sampai dengan bulan Desember 2017. Distribusi kuesioner beserta tingkat pengembalian kuesioner yang dapat diolah disajikanpada Tabel

Tabel 5.2

Rincian Pengiriman dan Pengembalian Kuesioner

\begin{tabular}{lc}
\hline \multicolumn{1}{c}{ Keterangan } & Jumlah \\
\hline Kuesioner yang diantar langsung ke responden & 77 \\
Kuesioner yang tidak dikembalikan & $(10)$ \\
Kuesioner yang dikembalikan responden & 67 \\
Kuesioner yang digunakan & 67 \\
Tingkat pengembalian (response rate): & $\mathbf{8 7 \%}$ \\
Kuesioner yang kembali_x 100\% $=\underline{67}$ x 100\% & \\
Kuesioner yang disebar & \\
\hline Sumber: Data primer (diolah) &
\end{tabular}

Tabel 5.2 di atas menunjukkan bahwa kuesioner yang tersebar ke responden sebanyak 77 kuisioner.Setelah konfirmasi dilakukan, hanya 67 kuisioner yang dikembalikan, sejumlah 10 kuisioner tidak dikembalikan karena kesibukan auditor yang bekerja di lapangan.Perhitungan dari data tersebut menghasilkan tingkat pengembalian responden yang dapat dianalisis (responden rate) sebesar 87 persen. 
I Dewa Md. Arik Permana Putra, dan Desak Kt. Sintaasih. Efek Moderasi Skeptisisme.....

\section{Karakteristik Responden}

Karakteristik responden dalam penelitian ini diuraikan pada Tabel 5.3.Data karakteristik responden merupakan data responden yang dikumpulkan untuk mengetahui profil responden penelitian. Dari hasil penelitian dapat diketahui gambaran tentang karakeristik responden yang meliputi empat aspek, yaitu: jenis kelamin, masa kerja, pendidikan terakhir, dan jabatan posisi auditor

Tabel 5.3 menunjukkan bahwa sebagian besar responden yaitu sebanyak 29 orang auditor dengan persentase 43 persen adalah laki-laki, sedangkan 38 orang responden dengan persentase 57 persen adalah perempuan.

Tabel 5.3

\begin{tabular}{rrr} 
Distribusi & $\begin{array}{r}\text { responden menurut Jenis } \\
\text { Terakhir dan } \\
\text { kantorAkuntan }\end{array}$ & $\begin{array}{c}\text { Kelamin, Mabatan auditor pada } \\
\text { Pablik di Provinsi Bali }\end{array}$ \\
\hline
\end{tabular}

\begin{tabular}{|c|c|c|c|}
\hline \multirow{2}{*}{ No } & \multirow{2}{*}{ Jenis Kelamin } & \multicolumn{2}{|c|}{ Jumlah } \\
\hline & & Orang & Persentase $(\%)$ \\
\hline $\mathbf{A}$ & Janis kelamin & & \\
\hline 1 & Laki-laki & 29 & 43 \\
\hline 2 & Perempuan & 38 & 57 \\
\hline & Jumlah & 67 & 100 \\
\hline B & Masa Kaerja & & \\
\hline 1 & 1-3 Tahun & 10 & 15 \\
\hline 2 & 4-6 Tahun & 20 & 30 \\
\hline 3 & 7-9 Tahun & 23 & 34 \\
\hline 4 & $>10$ Tahun & 14 & 21 \\
\hline & Jumlah & 67 & 100 \\
\hline $\mathbf{C}$ & Pendidikan Terakhir & & \\
\hline 1 & Diploma III & 17 & 25 \\
\hline 2 & PPAk/S1 & 41 & 62 \\
\hline 3 & $\mathrm{~S} 2$ & 9 & 13 \\
\hline Jumlah & & 67 & 100 \\
\hline D & Jabatan & & \\
\hline 1 & Junior Auditor & 27 & 40 \\
\hline 2 & Seniot Auditor & 40 & 60 \\
\hline & Jumlah & 67 & 100 \\
\hline
\end{tabular}

Sumber: Jawaban kuisioner (2017) 
Hal ini menjukkan bahwa sebagian besar adalah karyawan perempuan.Hal ini ada persepsi bahwa karyawan perempuan lebih cermat dan teliti.Masa kerja responden auditor sebanyak 23 auditor dengan persentase 34 persen bekerja 7-9 tahun.Sedangkan jumlah responden terkecil yaitu 10 orang dengan persentase 15 persen bekerja 1-3 tahun.Hal ini menujukkan bahwa auditor tergolong senior auditor, karena dengan masa kerja di atas tiga tahun diperlukan karena auditor bekerja sebagai auditor harus betul-betul menunjukkan professional seorang auditor.

Tingkat pendidikan auditor sebanyak 41 orang atau 62 persen orang responden memiliki tingkat pendidikan PPAk/S1 yang merupakan tingkat pendidikan terbanyak.Sedangkan, jumlah terkecil yaitu sebanyak 9 orang atau dengan persentase 13 persen berpendidikan S2.Dilihat dari tingkat jabatan senior auditor sebanyak 27 orang atau 40 persen, sedangkaan junior auditor sebanyak 40 orang dengan persentase 60 persen. Hal ini menunjukkan junior auditor lebih banyak daripada senior auditor yang berarti orang lebih muda dan orang lebih muda muda lebih kuat dalam bekerja.

\section{Uji Instrumen Penelitian}

Pengujian instrumen penelitian menggunakanuji validitasdan ujireliabilit as dengan menggunakan bantuan program Statistical Package Social Science (SPSS) versi 20.00. Uji Validitas, uji validitas merupakan pengujian intrumen penelitian sebagai suatu derajat ketepatan alat ukur penelitian.Syarat minimum suatu kuesioner untuk memenuhi validitas adalah jika korelasi antar butir dengan skor total tersebut positif dan nilainya lebih besar dari 0,30. 
I Dewa Md. Arik Permana Putra, dan Desak Kt. Sintaasih. Efek Moderasi Skeptisisme.....

Berdasarkan uji validitas menunjukkan bahwa 25 indikator yang digunakan memiliki nilai kolerasi 0,581-0.841 yang artinya lebih besar dari 0,3 hal ini menunjukkan bahwa instrumen penelitian yang digunakan telah memenuhi syarat validitas dan dapat dilanjutkan ke analisa berikutnya. Uji Reliabilitas, hasil uji reliabilitas ini menunjukkan nilai Alpha Cronbach's dalam uji reliabilitas variabel kompetensi $=0,779$, kompensasi $=0,672$, skeptisisme professional $=0,655$ dan variabel kinerja auditor $=0,876$. Nilai ini lebih besar dari 0,60 , hal ini berarti seluruh variabel dalam penelitian adalah reliabel.

\section{Hasil Analisis Regresi Moderasi (Moderated Regression Analysis/MRA)}

Hasil analisis regresi moderasi disajikan pada Tabel 5.14. Besarnya nilai Adjusted $\mathrm{R}$ square(adjusted $R^{2}$ )sebesar 0,366 yang berarti 36,6 persen variabel kinerja auditor dijelaskan oleh variabel kompetensi dan kompensasi yang dimoderasi oleh skeptisisme profesional. Sedangkan sisanya sebesar 63,4 persen dijelaskan oleh variabel lain yang tidak dimasukkan dalam model penelitian.

Uji F menghasilkan nilai $F_{\text {hitung }}$ sebesar 8,626 dengan signifikansi sebesar 0,000 lebih kecil dari $\alpha=0,05$ ( $\alpha=5$ persen), yang berarti bahwa model yang digunakan dalam penelitian ini telah layak (fit). Hasil analisi regresi moderasian ditunjukkan pada Tabel 5.14.Variabel bebas yang memiliki standadized coefficient beta terbesar yang berarti berpengaruh dominan terhadap variabel terikat.Tabel 5.14 menunjukkan bahwa interaksi kompetensi dengan skeptisisme professional berpengaruh dominan terhadap kinerja auditor pada kantor akuntan publik di Provinsi Bali, karena standadized coefficient beta interkasi $\mathrm{X}_{1} \cdot \mathrm{X}_{3}$ terbesar yakni 0,351 bernilai positif. 
Sedangkan koefisien regresi skeptisisme professional bernilai $-0,065$ ini menujukkan semakin menurun skeptisime auditor maka semakin lambat auditor menyelesaikan laporan auditor independen sehingga pada akhirnya kinerja auditor semakin menurun.

Tabel 5.14

Hasil Analisis Moderasian

\begin{tabular}{|c|c|c|c|c|c|}
\hline \multirow{2}{*}{ Variabel } & \multicolumn{2}{|c|}{$\begin{array}{l}\text { Unstandardized Coeff } \\
\text { icients }\end{array}$} & \multirow{2}{*}{$\begin{array}{l}\text { Standar } \\
\text { Coefficients } \\
\text { Beta }\end{array}$} & \multirow{2}{*}{$\mathbf{T}$} & \multirow{2}{*}{ Sig. } \\
\hline & B & $\begin{array}{c}\text { Std. } \\
\text { Error }\end{array}$ & & & \\
\hline (Constant) & $-0,092$ & 0,100 & & $-0,914$ & 0,364 \\
\hline Kompetensi $\left(\mathrm{X}_{1}\right)$ & 0,321 & 0,105 & 0,321 & 3,059 & 0,003 \\
\hline Kompensasi $\left(\mathrm{X}_{2}\right)$ & 0,257 & 0,108 & 0,257 & 2,382 & 0,020 \\
\hline Skeptisisme Prof. (X3) & $-0,065$ & 0,102 & $-0,065$ & $-0,644$ & 0,522 \\
\hline Moderasi $1\left(\mathrm{X}_{1} \cdot \mathrm{X}_{3}\right)$ & 0,320 & 0,105 & 0,351 & 3,059 & 0,003 \\
\hline Moderasi $2\left(\mathrm{X} 2 \mathrm{X}_{3}\right)$ & 0,244 & 0,118 & 0,240 & 2,059 & 0,044 \\
\hline $\mathrm{F}$ & 8,626 & & & & \\
\hline Sig F & 0,00 & & & & \\
\hline R Square & 0,41 & & & & \\
\hline Adjusted RSquare & 0,36 & & & & \\
\hline
\end{tabular}

\section{Hasil Uji Hipotesis (Uji t)}

Pengujian hipotesis penelitian ini menggunakan uji t. Pengujian hipotesis akan ditunjukkan sebagai berikut:

1) Pengujian Hipotesis $1\left(H_{1}\right)$. Nilai signifikansi $X_{1}$ adalah 0,003 yang berarti lebih kecil dari $\alpha=0,05$ dengan koefsien 0,321 . Hal ini menunjukkan bahwa terdapat pengaruhpositifdansignifikanterhadapkinerjaauditor.Simpulannyahip otesis 1 diterima.

2) Pengujian hipotesis $2\left(\mathrm{H}_{2}\right)$. Nilai signifikansi $X_{2}$ adalah 0,020 yang berarti lebih kecil $\alpha=0,05$ dengan koefisien 0,257. Hal inimenunujkkan bahwa 
I Dewa Md. Arik Permana Putra, dan Desak Kt. Sintaasih. Efek Moderasi Skeptisisme.....

terdapat pengaruh positif dan signifikan terhadap kinerjaauditor. Simpulannya hipotesis 2 diterima.

3) Pengujian hipotesis $3\left(\mathrm{H}_{3}\right)$. Nilai signifikansi $\mathrm{X}_{3}$ adalah 0,003 yang berarti lebih kecil $\alpha=0,05$ dengan koefisien 0,320 .Hal ini menunjukkan bahwa skeptisisme professional mampu memoderasi pengaruh kompetensi terhadap kinerja auditor. Simpulannya hipotesis 3 diterima.

4) Pengujian hipotesis 4. $\left(\mathrm{H}_{4}\right)$, Nilai signifikansi $\mathrm{X}_{4}$ 0,044 lebih kecil dari $\alpha$ $=0,05$ dengan koefisien $\beta 4$ positif 0,244. Hal ini menunujukkan bahwa skeptisisme profesional mampu memoderasi pengaruh kompensasi terhadap kinerja auditor. Simpulannya hipoetesis 4 diterima.

\section{Pengaruh Kompetensi pada Kinerja auditor}

Hasil analisis regresi moderasi, diketahui bahwa nilai signifikan sebesar 0,003 yang nilainnya lebih kecil dari tingkat signifikansi yang ditetapkan $(\alpha=0,05)$ dan memiliki koefisien regresi sebesar 0,321 . Sehingga hipotesis pertama $\left(\mathrm{H}_{1}\right)$ diterima yakni kompetensi terbukti berpengaruh positif dan signifikan terhadap kinerja auditor.

Hal ini terjadi karena semakin tinggi kompetensi yang dimiliki oleh auditor dan sesuai dengan tuntutan pekerjaan maka kinerja auditor akan semakin meningkat karena auditor yang kompeten biasanya memiliki kemampuan.Hasil penelitian ini mendukung penelitian yang dilakukan oleh Endah (2011), Yusri (2013) yang menyebutkan bahwa kompetensi berpengaruh positif terhadap kinerja auditor.Hasil penelitian ini mendukung 
hipotesispertama bahwa kompetensi berpengaruh terhadap kualitas audit. Hal ini berarti bahwa kualitas audit dapat dicapai jika auditor memiliki kompetensi yang baik.

Auditor sebagai ujung tombak pelaksanaan tugas audit memang harus senantiasa meningkatkan pengetahuan yangtelah dimiliki agar penerapan pengetahuan dapat maksimal dalam praktiknya. Hasil penelitian ini mendukung penelitian yang dilakukan oleh Anugerah et al., (2011), Anguo and Long (2014), Endah (2011), Emmyah (2009) bahwa pengalaman dan pengetahuan merupakan faktor penting yang berkaitan dengan pemberian opini audit, dimana dalam penelitian ini hal tersebut termasuk dalam risiko audit sebagai indikator pada kinerja auditor

\section{Pengaruh Kompensasi pada Kinerja auditor}

Berdasarkan hasil analisis regresi berganda, diketahui bahwa nilai signifikan sebesar 0,020 yang nilainya lebih kecil dari tingkat signifikan yang ditetapkan $(\alpha=0,05)$ dan memiliki nilai koefisien sebesar 0,257 . Sehingga hipotesis kedua diterima yakni kompensasi terbukti berpengaruh positif dan signifikan terhadap kinerja auditor.

Berkaitan dengan hal tersebut, maka organisasi perlu memberikan perhatian khusus terhadap kinerja yang diperoleh karyawan dengan cara pemberian kompensasi (hadiah, imbalan, dan penghargaan) dan motivasi untuk bekerja penuh semangat, memiliki 
I Dewa Md. Arik Permana Putra, dan Desak Kt. Sintaasih. Efek Moderasi Skeptisisme.....

tanggung jawab yang tinggi terhadap tugasnya, sehingga organisasi akan mudah memenuhi tujuan yang sudah direncanakan.

Hasil penelitian ini mendukung penelitian yang dilakukan Julianingtyas Abdul Hameed et al., (2014), Ayesha et al., (2015), Dito (2010) dan Dhermawan (2012) yang menunjukkan bahwa kompensasiberpengaruh positif terhadap kinerja auditor.Pemberian kompensasi yang adil dan layak akan meningkatkan ketekunan karyawan dalam bekerja (Emmanuel, 2013). Kompensasi yang diberikan diharapkan agar dapat meningkatkan kinerja karyawandalam melaksanakan tugas dan kewajibannya di dalam perusahaan (Dessler, 2004).Supiyanto (2015) menyatakan bahwa kompensasi berupa bonus diberikan kepada karyawan yang telah bekerja dengan baik.Penelitian sebelumnya yang dilakukan oleh Supatmi (2010) menyatakan bahwa kompensasi berpengaruh signifikan danpositif terhadap kinerja.Pertiwi (2013) dalam penelitiannya menyatakan bahwa variabel kompensasi berpengaruh positif dan signifikan terhadap kinerja secara keseluruhan bermakna bahwa semakin baik kompensasi karyawan maka kinerja auditor juga semakin meningkat.

\section{Efek Moderasi Skpetisisme Profesional Berpengaruh Pada Kompetensi terhadap Kinerja auditor}

Berdasarkan hasil analisisa moderasi, diketahui bahwa koefisien beta sebesar 0,320, dengan nilai signifikansi sebesar 0,003 yang nilainnya lebih kecil dari tingkat signifkan yang ditetapkan $(\alpha=0,05)$.Dengan demikian skeptisisme prifesional terbukti sebagai variabel moderasi.Hal ini menunjukan 
bahwa skeptisisme profesional memperkuat pengaruh kompetensi terhadap kinerja auditor.

Secara umum hal ini menggambarkan bahwa kompetensi mampu meningkatkan kinerja auditor apabila didukung oleh skeptisime profesional yang baik.Suatu sikap skeptisisme profesional berarti praktisi membuat suatu penilaian kritis dengan selalu mempertanyakan bukti audit dan selalu waspada terhadap bukti yang kontradiktif (IAI 2013:40).

Hal ini sesuai dengan hasil penelitian Safwan dkk., (2014) yang menyatakan bahwa skpetisime profesional berpengaruh positif dan signifikan pada kinerja auditor (Sutrisno dan Fajarwati 2014, Suzy 2008, Anugerah dkk., 2011, Taylor 2015 dan Tersno dkk., 2016).

\section{Efek Moderasi Skeptisisme profesional Berpengaruh Pada Kompensasi pada Kinerja auditor}

Berdasarkan hasil analisis moderasi.diketahuibahwa nilai signifikan sebesar 0,044 yang nilainnya lebih kecil dari tingkat signifikansi yang ditetapkan $(\alpha=0,05)$ dan memiliki koefisien regresi sebesar 0,244.Dengandemikian,skeptisisme profesional terbukti sebagaivariabel moderasi.

Secara umum hasil ini menggambarkan bahwa kompensasi mampu meningkatkan kinerja auditor apabila didukung dengan askeptisional profesional yang baik.Skeptisisme profesional dapat memberikan sugesti pada perilaku yang ditanamkan organisasi agar dapat menyelesaikan tugas dengan sukses, dan memberikan keuntungan pada auditor itu sendiri. 
I Dewa Md. Arik Permana Putra, dan Desak Kt. Sintaasih. Efek Moderasi Skeptisisme.....

Skeptisisme profesional adalah sikap yang mencakup pikiran yang selalu mempertanyakan dan melakukan evaluasi secara kritis bukti audit.Auditor menggunakan pengetahuan, keterampilan, dan kemampuan yang dituntut oleh profesi akuntan publik untuk melaksanakan dengan cermat dan seksama, dengan maksud baik dan integritas, pengumpulan dan penilaian bukti audit secara objektif (PSA No. 4 SA seksi 230). Dengan demikian kompensasi akan mempengaruhi kinerja auditor ketika skeptisisme professional akan semakin baik (Anugerah dkk., 2011, Taylor 2015 dan Tersno dkk., 2016).

\section{SIMPULAN DAN SARAN}

Berdasarkan hasil analisis dan pembahasan pada bab-bab sebelumnya dari variabel sistem kompetensi, Kompensasi dan Skeptisisme profesional, maka dapat disimpulkan bahwa: Kompetensi berpengaruh positif dan signifikan terhadap kinerja auditor. Hal ini berarti semakin tinggi kompetensi yang dimiliki oleh auditor dan sesuai dengan tuntutan pekerjaan maka kinerja auditor akan semakin meningkat. Kompensasi berpengaruh positif dan signifikan terhadap kinerja auditor. Hal ini berarti semakin baik kompensasi maka akan semakin tinggi juga kinerjanya. Skeptisisme profesional memperkuat pengaruh kompetensi terhadap kinerja auditor, yang berarti kompetensi secara signifikan mampu meningkatkan kinerja auditor apabila didukung oleh skeptisisme profesional yang baik. Skeptisisme profesional memperkuat pengaruh kompensasi terhadap kinerja auditor, yang berarti kompensasi yang didukung oleh skeptisisme profesional yang baik secara signifikan mampu meningkatkan kinerja auditor. 
Berdasarkan simpulan diatas, maka saran dalam penelitian ini antara lain: Memperhatikan dan melaksanakan dengan sunggug-sungguh indikator nomor dua dari variabel kompetensi yakni menyelesaikan pekerjaan secara independen karena sikap ini harus dimiliki seorang auditor. Sikap independen maknanya tidak memihak kesalah satu pihak, baik agen ataupun prinsipal walupun dua-duanya membutuhkan kepentingan audit. Prinsipal kantor akuntan publik memperhatikan dan memberikan asuransi ketenagakerjaan yang merupakan indikator keempat dari variabel kompensasi kepada auditor karena asuransi tersebut merupakan jaminan kerja buat mereka karena dengan diberikan asuransi maka auditor akan ada kepuasan kerja. Auditor harus selalu bersikap hati-hati dan tekun karena kedua sikap ini diperlukan dalam proses pengauditan sehingga meminta bukti, menelusuri bukti dan menganalisis bukti mutlak di perlukan. Kedua sikap ini merupakan indikator pertama dari variabel skeptisisme professional sehingga memberikan opini yang merupakan keharusan seorang auditor akan bisa terpenuhi apabila sikap-sikap ini diperhatikan dan ditaati. Memiliki insisiatif menyelesaikan pekerjaan merupakan indikator kelima dari variabel kinerja. Sikap indikator ini diperlukan karena seorang auditor sebagai pekerja di klien sangat dibutuhkan. Oleh karena itu, seorang auditor harus mempunyai insiatif menyelesaikan pekerjaan karena pekerjaan audit tersebut tidak akan pernah selesai.

\section{REFERENSI}

Abdul Hameed, Muhammad Ramzan, Hafiz M. Kashif Zubair, Ghazanfar Ali, and Muhammad Arslan. 2014. Impact of Compensation on Employee 
I Dewa Md. Arik Permana Putra, dan Desak Kt. Sintaasih. Efek Moderasi Skeptisisme.....

Performance (Empirical Evidence from Banking Sector of Pakistan). International Journal of Business and Social Science. 5 (2) pp: 302-309

Achmad S.Ruky. 2006. Sistem Manajemen Kinerja. Jakarta : PT Bumi Aksara.

Afnita Mita, Mahlia Muis, Fauziah Umar. 2014. Pengaruh Budaya Organisasi dan Kompensasi terhadap Kinerja Karyawa Di BPJS Ketenagakerjaan Kantor Pusat. Jurnal Analisis.3 (2) hal: 172-179

Agoes, Sukrisno. 2012. Auditing: Petunjuk Praktis Pemeriksaan Akuntan oleh Akuntan Publik. Edisi 4 Buku1. Jakarta: Salemba Empat

Anugerah, Rita, Ria Nelly Sari, dan Rina Mona Frostiana. 2011. The Relationship Between Ethics, Expertise, Audit Experience, Fraud Risk Assessment, and Audit Situational Factors and Auditor Professional Skepticism. International Symposium on Finance and Accounting. 2011.

Anguo $\mathrm{Xu}$ and Long Ye.2014. Impacts of Teachers' Competency on Job Performance in Research Universities with Industry Characteristics: Taking Academic Atmosphere as Moderator Anguo Xu1, Long Ye Impacts of Teachers' Competency on Job Performance in Research Universities with Industry Characteristics: Taking Academic Atmosphere as Moderator. Journal of Industrial Engineering and Management. 7(5) pp: 1283-1292.

Ayudiati, Soraya Eka. 2010. Analisis Pengaruh Locus of Control Terhadap Kinerja dengan Etika Kerja Islam sebagai variabel Moderating (Studi pada Karyawan tetap Bank Jateng Semarang). Skripsi. Semarang: Fakultas Ekonomi Universitas Diponogoro.

Ayesha Aslam, Amna Ghaffar, Tahleel Talha, and Hina Mushtaq. 2015. Impact of Compensation and Reward System on The Performance of An Organization: An Empirical Study on Banking Sector of Pakistan.European Journal of Business and Social Sciences. 4 (08) pp: $319-325$

Azad, Ali N. 1994. Time Budget Pressure and Filtering of Time Practices in Internal Auditing: A Survey. Managerial Auditing Journal. 9 (6):17-25.

Badera, I Dewa Nyoman. 2004. Pengaruh kesesuaian Hubungan Corporate GopernancaPada Kinerja Keuangan. Disertasi. Yogyakarta: Universitas Gajah Mada 
Brownell, Peter. 1982. The Role of Accounting Data in Performance Evaluation, Budgetary Participation, and Organizational Effectiveness. Journal of Accounting Research, Vol 20, pp 12-27.

Chen, Qiu, Khim Kelly, dan Steven E. Salterio. 2009. Do Audit Actions Consistent with Increased Auditor Scepticism Deter Potential Management Malfeasance?.Jurnal dipresentasikan dalam ABO Research Conference, 9-10 Oktober 2009. Seatle, Washington.

Darmawati, Deni, Khomsiyah, dan Rika Gelar Rahayu. 2004, "Hubungan Corporate Governance dan Kinerja Perusahaan," Simposium Nasional Akuntansi VII, Denpasar

Dessler, Gary. 2004. Manajemen Sumber Daya Manusia, Edisi 9, Jilid 1. Jakarta: Gramedia,

Dhermawan, Anak Agung Ngurah Bagus, I Gede Adnyana Sudibya, I Wayan Mudiartha Utama. 2012. Pengaruh Motivasi, Lingkungan Kerja, Kompetensi,Dan Kompensasi Terhadap Kepuasan Kerja Dan KinerjaPegawai Di Lingkungan Kantor Dinas Pekerjaan Umum provinsi Bali. Jurnal Manajemen, Strategi Bisnis, dan Kewirausahaan. 6 (2) hal: 173184

Dito, Anoki Herdian and Eisha Lataruva. 2010. Pengaruh Kompensasi terhadap Kinerja Karyawan PT. Slamet Langgeng Purbalingga dengan Motivasi Kerja sebagai Variabel Intervening. Tesis.http://eprints.undip.ac.id/23253/. Diunduh tanggal 23 April 2017

Donelly, David P., Jeffrey J. Q , and David O. 2003. "Auditor Acceptance of Dysfungsional Audit Behaviour : An Explanatory Model Using Auditors' Personal Characteristics,' Journal of Behaviour Research in Accounting, 15 (4), pp. 87-110.

Endah Wulandari. 2011. "Pengaruh Kompetensi, Independensi, dan komitmen organisasi terhadap kinerja auditor pada BPKP perwakilan DIY”. Jurnal Ekonomi dan Bisnis, 1 (1), pp. 31-41

Emmanuel Erastus Yamoah. 2013. Relationship Between Compensation and Employee Productivity. Singaporean Journal Of Business Economics, and Management Studies. 2(1) pp: 110-114

Eisenhardt, Kathleem. 1989. Agency Theory: An Assesment and Review. Academy of Management Review, 14. Hal 57-74.

Emmyah. 2009. Pengaruh Kompetensi terhadap Kinerja Pegawai pada Politeknik Negeri Ujung Pandang. Tesis. Program Magister Ilmu 
I Dewa Md. Arik Permana Putra, dan Desak Kt. Sintaasih. Efek Moderasi Skeptisisme.....

Administrasi Sekolah Tinggi Ilmu Admnistrasi Lembaga Administrasi Negara Makassar

Fadli, Ahmad. 2004. Pengaruh Gaya Kepemimpinan Terhadap KinerjaKaryawan Pada PT. Kawasan Industri Medan. Jurnal. Universitas Sumatra Utara, Medan.

Fianka. 2008. Teori Kinerja.wordpress.co .diupoload 23 April 2017

Financial Reporting Council. 2010. Auditor Scepticism : Raising the Bar. London: The Auditing Practices Board.

Forehand, Mark R. dan Sonya Grier. 2002. When Is Honesty The Best Policy? The Effect of Stated Company on Consumer Skepticism.Forthcoming, Journal of Consumer Psychology. Stanford University.

Fitriany. (2010). Analisis Komprehensif Pengaruh Independensi dan Kompetensi Auditor terhadap Kualitas Audit.Disertasi Pascasarjana Ilmu Akuntansi Universitas Indonesia.

Ghani, Ahmad Zaini. 2016. Pengaruh Kompetensi dan Trainability pada Kinerja (Studi pada Tenaga Kependidikan Senior di Universitas Sebelas Maret Surakarta). Tesis. Universitas Sebelas Maret Surakarta

Ghozali, Imam. 2006. Aplikasi Analisis Multivariate dengan Program SPSS. Cetakan Keempat. Semarang: Badan Penerbit Universitas Diponegoro.

Govindarajan, V. 1986. "Impact of Participation in the Budgetary Process on Managerial Attitude and Performance: Universalistic and Cintigency Perspective". Decission Sciences. Hal. 496-516.

Gusti, Maghfirah dan Syahril Ali. 2008. "Hubungan Skeptisisme Profesional Auditor Dan Situasi Audit, Etika, Pengalaman Serta Keahlian Audit Dengan Ketepatan Pemberian Opini Auditor Oleh Akuntan Publik”. Simposium Nasional Akuntansi XI. Padang.

Handoko, Yunus 2010. Pengaruh Pemberian Kompensasi terhadap Produktivitas kinerja karyawan di Peguruan tinggi Malang. Jurnal Ilmiah Bisnis dan Ekonomi ASIA. 5 (1) Hal: 112-129

Hartono Jogiyanto, 2004, Metodologi Penelitian Bisnis: Salah Kaprah dan Pengalaman, Edisi 2004-2005, BPFE, Yogyakarta. 
Hurtt, R. Kathy. 2010. Development of a Scale to Measure Professional Skepticism. Auditing: A Journal of Practice and Theory. American Auditing Association.

Ibojo Bolanle Odunlami, Asabi Oludele Matthew. 2014. Compensation Management and Employees Performance in the Manufacturing Sector, A Case Study of a Reputable Organization in the Food and Beverage Industry. International Journal of Managerial Studies and Research (IJMSR). 2 (9) pp: 108-117

Indriantoro, N., dan B. Supomo. 2012. Metode Penelitian Bisnis Untuk Akuntansi dan Manajemen. Yogyakarta: Penerbit BPFE.

Institut Akuntan Publik Indonesia-Kompartemen Akuntan Publik (IAPI-KAP). (2011). Standar Profesional Akuntan Publik. Jakarta: Salemba Empat.

Islahuzzaman. 2012. Istilah-istilah Akuntansi \& Auditing. Jakarta: PT. Bumi Aksara.

Jalaluddin. 2010. Pengaruh Environment Control Terhadap Hubungan Antara Partisipasi Anggaran dengan Kinerja Pemerintah (Studi Empiris pada SKPD Di Kabupaten Aceh Besar). Jurnal Telaah \& Riset Akuntansi. Vol. 3. N0. 1 , Hal. 84-99.

Jensen, M. C and Meckling, W.H. 1976. Theory of the Firm : Managerial Behavior, Agency Costs and Ownership Structure. Journal of Financial Economics, Oktober, 1976, V. 3, (4), pp. 305-360.

Kalbers, Lawrence P. dan Fogarty, Timothi J. 1995. "Profesionalism and Its Consequences: A Study of Internal Auditors", Auditing: A Journal of Practice and Theory, 14: 64-86. Ohio.

Kathy Hurtt, M. E. 2003. Professional Scepticism: A Model with Implication for Reseacrh, Practise, and Education. Working Paper, University of Wisconsin

Kolibáčová, Gabriela. 2014. The Relationship Between Competency and Performance. Acta Universitatis Agriculturae et Silviculturae Mendelianae Brunensis. 62 (6), pp: 1315-1327

Kuang Chi, et. Al. 2007. Investigating the relationship among leadership styles,emotional intelligence ang organization commitmen on job performance: A study of sales people in Thailand. Journal of human Resource and Adultlearning, 3 (2), Pp. 112-145 
I Dewa Md. Arik Permana Putra, dan Desak Kt. Sintaasih. Efek Moderasi Skeptisisme.....

Lotunani, Alamsyah; M.S Idrus; Eka Afnan; and Margono Setiawan. 2014. The Effect of Competence on Commitment, Performance and Satisfaction with Reward as a Moderating Variable (A Study on Designing Work plans in Kendari City Government, Southeast Sulawesi). International Journal of Business and Management Invention. 3 (2) pp: 18-25

Lee, T. dan Mary Stone, 1995. Competence and Independence: The Congenial Twins Of Auditing? Business Finance and Accounting, 22 (8), pp. 11691177

Mahmun, M. Toha. 2016. Pengaruh Disiplin dan Kompensasi terhadap Kinerja Pegawai Unit Pelaksana Teknis (UPT) Perpustakaan Universitas Sriwijaya,.https://www.scribd.com/ document258213982/Pengaruh-Lingkungan-Kerja-Dan-Kepuasan-KompensasiTerhadap-Kinerja-Karyawan. Diunduh tanggal 23 April 2017

Mangkunegara, A.A. Anwar Prabu. 2010. Perilaku dan Budaya Organisasi. Bandung: Refika Aditama.

Mathis, dan Jackson. 2002. Manajemen Sumber Daya Manusia, Edisi pertama, Cetakan Pertama, Yogyakarta : Salemba Empat

Mathis,Robert L dan Jhon H. Jackson.2009. Human Resource Management. Jakarta: Salemba Empat.

Mulyadi. 2002. Auditing. (edisi ke 6). Jakarta: Salemba empat

Nizarul M. Alim, Trisni Hapsari, dan Liliek Purwanti. 2007. Pengaruh Kompetensi dan Independensi Terhadap Kualitas Audit Dengan Etika Auditor Sebagai Variabel Moderasi.Simposium Nasional Akuntansi. Unhas Makasar 26-28 Juli. Hal.: 1-26

Panggabean, Mutiara S, 2002. Manajemen Sumber Daya Manusia. Jakarta: Ghalia Indonesia.

Patrick K. Mwangi. 2014. The Effect of Compensation on Employee Motivation: A Case Study of Chloride Exide. Nairobi: United States International University.

Pfeffer .J, Soetjipto Budi W, Handoko T. Hani, dkk. 2003. Paradigma Baru Manajemen Sumber Daya Manusia. Editor A. Usmara, Cetakan Keempat, Edisi Kedua, Yogyakarta: Amara Books.

Pratiwi, Agustin. 2013 Pengaruh Kompensasi Terhadap Kinerja Karyawan Pada PT. Pos Indonesia (Persero) Kantor Cabang Bangkalan.Jurnal Pengaruh Kompensasi Terhadap Kinerja Karyawan. 1 (1) Hal: 1-12 
Quadackers, Mathias Lucas. 2009. A Study of Auditors Skeptical Characteristics and Their Relationship to Skeptical Judgements and Decision. Dissertation of Amsterdam University.

Rahyuda, I Ketut, Wayan Murjana Yasa, Ni Nyoman Yuliarmi. 2004. Metodologi Penelitian. Fakultas Ekonomi Universitas Udayana.

Rantesalu, Agustina; Abdul Rahman Mus; Mapparenta; dan Zaenal Arifin. 2016. "The Effect of Competence, Motivation and Organizational Culture on Employee Performance: the Mediating Role of Organizational Commitment".Quest Journals Journal of Research in Business and Management. 4 (9) pp: 08-14

Rahmah Ismail and Syahida Zainal Abidin. 2010. Impact of workers' competence on their performance in the Malaysian private service sector. Peerreviewed \& Open access journal. 2 (2) pp: 25-36

Rivai, Veithzal Saga dan Ella Jauvani. 2010. Manajemen Sumber Daya Manusia untuk Perusahaan. Jakarta: PT. Rajagrafindo Jakarta.

Robbins, Stephen P \& Judge, Timothy A. 2013.Organizational Behavior. Edition 15. New Jersey: Pearson Education

Safwan, Nadirsyah, Syukriy Abdullah. 2014. Pengaruh Kompetensi Dan Motivasi Terhadap Kinerja Pengelolaan Keuangan Daerah pada Pemerintah Daerah kabupaten Pidie Jaya. Jurnal Akuntansi Pascasarjana Universitas Syiah Kuala. 3 (1) hal: $133-139$

Simamora, Henry. 2004. Manajemen Sumber Daya Manusia, Edisi Ketiga, Cetakan Pertama, Yogyakarta: STIE-YKPN.

Simamora, Henry. 2006. Manajemen Sumber Daya Manusia, Edisi III. Yogyakarta : STIE YKPN.

Smith \& Bertozzi. 1998. Principal Agent: An Explanatory model of public budgeting. Journal of Public Budgeting, Accounting and Financial Manageent (fall). 325-353.

Sugiyono. 2014. Metode Penelitian Kuantitatif, Kualitatif, dan Kombinasi (Mixed Methods). Bandung : Alfabeta 
I Dewa Md. Arik Permana Putra, dan Desak Kt. Sintaasih. Efek Moderasi Skeptisisme.....

Supatmi, Mamik Eko; Umar Nimran; dan Hamidah Nayati Utami. 2010. Pengaruh pelatihan, kompensasi terhadap kepuasan kerja karyawan dan kinerja karyawan. Jurnal Profit. 7 (1) hal: 25-37

Supiyanto, Yudi. 2015. Pengaruh Kompensasi, Kompetensi dan Komitmen Organisasi terhadap Kepuasan dan Kinerja. Jurnal Economia. 12 (2) Hal: $118-138$

Sutrisno dan Diana Fajarwati. 2014. Pengaruh Pengalaman, Keahlian, Situasi Audit, Etika, dan Gender terhadap Ketepatan Pemberian Opini Auditor melalui Skeptisisme Profesional Auditor (Studi Kasus pada KAP di Bekasi).Jurnal Riset Akuntansi Keuangan. 5 (2), 1-15.

Sutrisno. 2010. Pengaruh Partisipasi, Motivasi, dan pelimpahan Wewenang dalam penyusunan Anggaran Terhadap Kinerja Manajerial (Studi Empiris Pada Dinas Daerah dan Lembaga Teknis Daerah di Kabupaten Rembang). Tesis. Universitas Diponegoro.

Suzy Noviyanti. 2008. Skeptisme Profesional Auditor dalam Mendeteksi Kecurangan. Jurnal Akuntansi dan Keuangan Indonesia, Vol.5, No.1, 102- 125 .

Trisnaningsih, Sri. 2007. Independensi Auditor dan Komitmen Organisasi sebagai Mediasi pengaruh Pemahaman Good Governance, Gaya Kepemimpinan dan Budaya Organisasi terhadap Kinerja Auditor. Simposium Nasional Akuntansi X.

Taylor Holstrom. 2015. The Effect of Time Pressure on Professional Skepticism levels exhibited by Student Auditore.Disertation.Departmental Honors in the Department of Accounting Texas Christian University.

Tresno Eka Jaya, Irene dan Chitul.2016. Skepticism, Time Limitation of Audit, Ethics of Professional Accountant and Audit Quality (Case Study in Jakarta, Indonesia). Review Integrtive Bussiness Economics. 5 (3) PP 173- 182

Umam, Kaherul. 2010. Perilaku Organisasi. Bandung: Pustaka Setia

Wardhana, Surya Gede Ary, Ni Ketut Rasmini, Ida Bagus Putra Astika. 2015. Pengaruh Kompetensi pada Akuntabilitas Kinerja Instansi Pemerintah dengan Komitmen Organisasi sebagai Variabel Moderasi. E- Jurnal Ekonomi dan Bisnis Universitas Udayana. 4 (9) hal: 571-598

Yusri Kalsim. 2013. “ Pengaruh Akuntabilitas, Kompetensi, Dan Kompleksitas Tugas Terhadap Kinerja Auditor". JurnalAkuntansi Pascasarjana Universitas Syiah Kuala ISSN 2302-0164, 2 (2), pp.103-116 